\title{
Patrón de atenuación en mosaico
}

\section{Mosaic Attenuation}

Ana Manzano, MD(1), Carlos Celis Preciado, MD ${ }^{(2)}$

(1)Radióloga, Departamento de Radiología, Hospital Universitario San Ignacio. Pontificia Universidad Javeriana. Bogotá, Colombia.

(2)Internista, Neumólogo, Unidad de Neumología, Hospital Universitario San Ignacio. Pontificia Universidad Javeriana. Bogotá, Colombia.

Correspondencia: Ana Cristina Manzano, Correo electrónico: acmanzano@javeriana. edu.co

Recibido: 12-03-2014. Aceptado: 25-03-2014.
El Glosario de la Sociedad Fleishner define este hallazgo como un mosaico de regiones de atenuación heterogénea con bordes bien definidos correspondientes a los lobulillos pulmonares secundarios (1).

Es un signo escanográfico exclusivamente, y se refiere al aspecto heterogéneo en la atenuación del pulmón, consistente en áreas alternantes de mayor y menor densidad (figura 1). Las tres principales causas de este patrón son enfermedad vascular pulmonar, enfermedad parenquimatosa y enfermedad bronquiolar.

\section{Enfermedad vascular pulmonar}

La distribución del patrón de atenuación en mosaico en la hipertensión arterial pulmonar se describe como heterogéneo o parcheado con distribución perivascular, que difiere de la segmentaria/subsegmentaria y bien definida observado en tromboembolismo pulmonar crónico; en este caso, raramente puede ocurrir atrapamiento de aire, posiblemente por broncoconstricción en el pulmón hipoperfundido (figura 2). En enfermedad pulmonar veno-oclusiva, el patrón de atenuación en mosaico se ha descrito hasta en $50 \%$ de los casos con confirmación histológica de la entidad (2-5).

\section{Enfermedad parenquimatosa}

En estos casos la atenuación en mosaico es debida a opacidad en vidrio esmerilado secundaria a compromiso intersticial u ocupación de los alvéolos con líquido, células o fibrosis interpuestos con pulmón normal de baja atenuación. No se asocia con variaciones regionales en el tamaño de los vasos y los cortes en espiración típicamente muestran disminución normal $\mathrm{y}$ uniforme en el volumen pulmonar e incremento en la atenuación del parénquima afectado (2-5).

Este patrón se ha descrito en neumonía por Pneumocystis jirovecii y también en neumonías bacterianas; en las neumonías intersticiales idiopáticas se presenta con mayor en casos de neumonía intersticial descamativa y más raramente en la intersticial inespecífica y la usual.

En neumonitis de hipersensibilidad el patrón de atenuación en mosaico puede estar presente en cualquier estadio y es el hallazgo radiológico más frecuente; puede asociarse con atrapamiento de aire, secundario a bronquiolitis celular.

\section{Enfermedad bronquiolar}

El patrón de atenuación en mosaico se presenta en cualquier patología que cursa con obstrucción de la vía aérea. Se ha descrito en bronquiolitis constrictiva idiopática y secundaria a infección, lesión por inhalación, enfermedad injerto contra hospedero, trasplante pulmonar y artritis reumatoide. Así mismo, es un hallazgo inespecífico en 


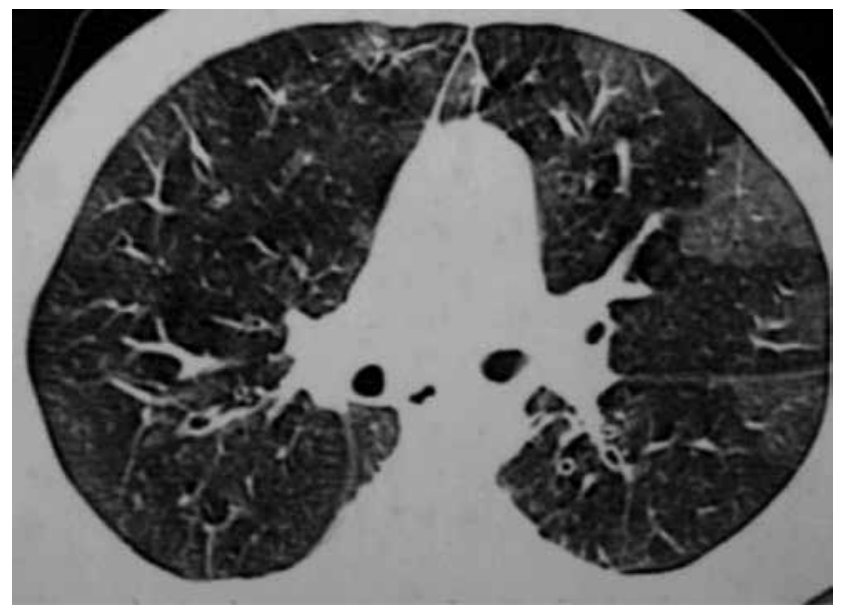

Figura 1. Patrón de atenuación en mosaico. Aspecto heterogéneo, parcheado de la atenuación pulmonar en el que alternan áreas de mayor y menor densidad.

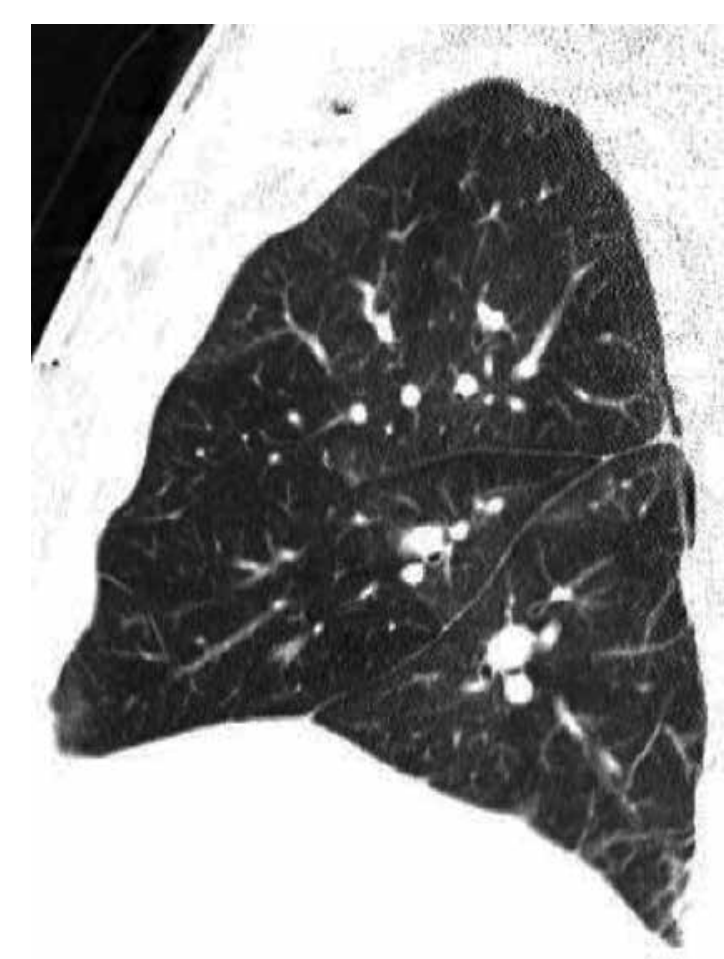

Figura 2. Tromboembolismo pulmonar crónico. Obsérvense las áreas alternantes de mayor y menor densidad. Es evidente la pérdida de la relación arteria/ bronquio en la región central y disminución en el tamaño de los vasos periféricos por hipertensión pulmonar.

neumonía criptogénica en organización y junto con atrapamiento de aire se describe en neumonitis de hipersensibilidad subaguda.
La obstrucción bronquiolar ocasiona atrapamiento de aire de lobulillos secundarios, alternados con lobulillos normales, lo cual da el aspecto característico de atenuación en mosaico que se hace más aparente en los cortes en espiración. Dada la vasoconstricción que acompaña estas áreas hipoxémicas del pulmón, las zonas de menor atenuación tienen menor número y tamaño de vasos, hallazgo que permite diferenciarlo de opacidad parcheada en vidrio esmerilado.

El patrón de atenuación en mosaico y el atrapamiento de aire son signos indirectos de asma y cuando comprometen más de un tercio del pulmón son indicadores sensibles de su severidad (figura 3).

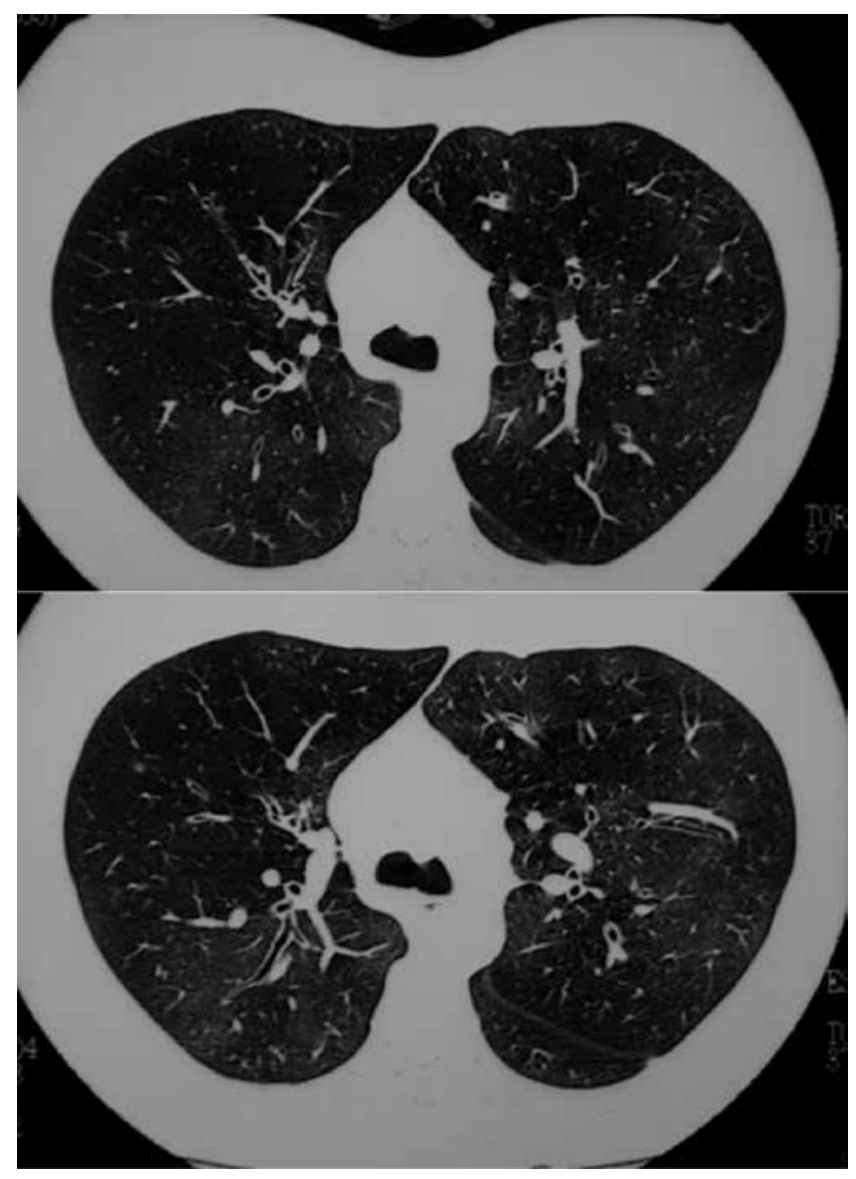

Figura 3. Crisis asmática severa. Obsérvese el aspecto parcheado de la transparencia pulmonar (imagen superior). Las áreas de mayor atenuación, que no atrapan aire, se hacen más aparentes en los cortes en espiración (imagen inferior) mientras que las áreas que atrapan aire permanecen lúcidas e hiperaireadas. Nótese la disminución en la vascularización de las áreas hipodensas de atrapamiento de aire. 
Tabla. Causas de patrón de atenuación en mosaico (1-5).

\begin{tabular}{|l|}
\hline 1-Enfermedad vascular pulmonar \\
\hline -Hipertensión pulmonar primaria \\
\hline -Tromboembolismo pulmonar crónico \\
\hline -Enfermedad pulmonar veno-oclusiva \\
\hline 2-Enfermedad intersticial \\
\hline -Neumonía por Pneumocystis jirovecii \\
\hline -Neumonía intersticial descamativa \\
\hline -Neumonitis de hipersensibilidad \\
\hline 3-Enfermedad bronquiolar \\
\hline -Bronquiolitis constrictiva \\
\hline -Neumonía criptogénica en organización \\
\hline -Neumonitis de hipersensibilidad \\
\hline -Bronquiolitis celular \\
\hline -Asma \\
\hline
\end{tabular}

\section{Bibliografía}

1. Hansell DM, Bankier AA, MacMahon H, McLoud TC, Müller NL, Remy J. Fleischner Society: glossary of terms for thoracic imaging. Radiology 2008; 246: 697-722.

2. Stern EJ, Swensen SJ, Hartman TE, Frank MS. CT mosaic pattern of lung attenuation: distinguishing different causes. AJR Am J Roentgenol. 1995;165: 813-6.

3. Stern EJ, Müller NL, Swensen SJ, Hartman TE. CT mosaic pattern of lung attenuation: etiologies and terminology. J Thorac Imaging. 1995;10: 294-7.

4. Worthy SA, Müller NL, Hartman TE, Swensen SJ, Padley SP, Hansell DM. Mosaic attenuation pattern on thin-section CT scans of the lung: differentiation among infiltrative lung, airway, and vascular diseases as a cause. Radiology. 1997;205: 465-70.

5. Ridge CA, Bankier AA, Eisenberg RL. Mosaic attenuation. AJR Am J Roentgenol. 201;197: W970-7. 